\title{
Forma urbana e polvição atmosférica: impactos na cidade do Rio de Janeiro
}

\author{
Urban form and atmospheric pollution: assessing impacts in Rio de Janeiro
}

Juliana Lúcio Motta Maia[a] (iD) Vinicius M. Netto [b] (iD), Bruno Lucian Gonçalves da Costa [c] (iD)

[a] Universidade Federal do Rio de Janeiro (ProUrb-UFRJ), Rio de Janeiro, RJ, Brasil

[b] Universidade Federal Fluminense (UFF), Niterói, RJ, Brasil

[c] Fundação Getúlio Vargas (FGV), Escola de Matemática Aplicada (EMAp), Rio de Janeiro, RJ, Brasil

Como citar: Maia, J. L. M., Netto, V. M., \& Costa, B. L. G. (2019). Forma Urbana e Poluição Atmosférica: Impactos na cidade do Rio de Janeiro. urbe. Revista Brasileira de Gestão Urbana, v.11, e20180145. DOI https://doi.org/10.1590/2175-3369.011. e20180145

\section{Resumo}

Cidades crescem em importância como polos de concentração de população, assim como em seu papel potencial como fontes de poluição atmosférica. Este artigo investiga possíveis impactos de aspectos da forma urbana nas concentrações desses contaminantes. Dado que esse é um tema ainda incipiente em estudos urbanos no Brasil, a pesquisa traz uma abordagem panorâmica do problema. 0 artigo discute 0 estado da arte sobre interações entre poluição, elementos naturais e condições climáticas. Expõe uma série de impactos da poluição do ar para a população e o meio ambiente e as interações entre a qualidade do ar e forma urbana apontando a carência de pesquisas na área. Em seguida, desenvolve uma forma de modelagem e avaliação dessas relações, e apresenta um estudo de caso na cidade do Rio de Janeiro envolvendo métodos estatísticos aplicados aos poluentes monóxido de carbono (CO), dióxido de enxofre $\left(\mathrm{SO}_{2}\right)$ e partículas inaláveis (PI); a variáveis morfológicas (taxa de ocupação e percentagem de verticalização de quadras); e meteorológicas (direção e velocidade do vento, precipitação pluvial e temperatura do ar). A pesquisa encontra indícios de relações entre forma urbana e poluentes atmosféricos, apontando graus de influência da taxa de ocupação e da verticalização na concentração dos poluentes considerados, e sugere novas frentes de abordagem empírica e metodológica.

Palavras-chave: Forma urbana. Poluição. Qualidade do ar. Morfologia. Desempenho.

\begin{abstract}
As cities have increased their role in concentrating the world's population, they have also become critical sources of pollution. This article investigates the possible impacts of urban form on air pollutant concentrations. Given the nascent state of this research field in urban studies in Brazil, we start with a panoramic view of the problem. Then the paper discusses the state of the art on interactions between
\end{abstract}

JLMM é arquiteta e urbanista, mestra em Arquitetura e Urbanismo, doutoranda em Arquitetura e Urbanismo, e-mail: juliana.musarq@ufrj.br VMN é arquiteto e urbanista, Ph.D. Advanced Architectural Studies, e-mail: vmnetto@id.uff.br

BLGC é mestre em Modelagem Matemática da Informação, e-mail: bruno.lucian.costa@gmail.com 
pollution, natural elements and climate conditions; explores some air pollution impacts on humans and the environment, and the literature on relations between air quality and urban form, pointing to a general lack of research in the field. It suggests a way of modeling and testing these relation in a case study in the city of Rio de Janeiro. It does so exploring statistical methods to understand the distribution of key urban pollutants, namely sulfur dioxide ( $\mathrm{SO}_{2}$ ), carbon monoxide (CO) and particulate matters (PM); along with morphological variables (ground space index and building verticality); and meteorological factors (wind direction and speed, rainfall and air temperature). Results point to grades of influence of the ground space index and building verticality on pollutants concentration and suggest new avenues for empirical and methodological work.

Keywords: Urban form. Pollution. Air quality. Morphology. Urban performance.

\section{Introdução}

A atividade humana e sua concentração em assentamentos urbanos vêm sendo associadas a um progressivo aumento da degradação do meio ambiente. Dentre fatores de degradação, a poluição atmosférica e a qualidade do ar tem tido posição de destaque devido ao seu poder de atingir grandes parcelas da população e do ambiente (Castro et al., 2003). Considerando a importância das cidades como polos de concentração populacional e fontes emissoras de poluentes, este trabalho investiga possíveis impactos da forma física urbana nas concentrações de poluentes. Examinaremos se diferenças morfológicas associadas à Taxa de Ocupação (TO) e ao percentual de verticalização (VERT) arquitetônica nas quadras podem impactar a concentração de poluentes no ar, como o Monóxido de Carbono (CO), o Dióxido de Enxofre (SO2) e as Partículas Inaláveis (PI) e, consequentemente, a qualidade do ar.

A investigação do desempenho ambiental da forma urbana parte dos impactos da poluição atmosférica na saúde de seres humanos, animais e vegetais, temas amplamente discutidos na literatura e na esfera pública. Examinando a bibliografia sobre as relações entre a cidade, clima e poluição do ar reunimos alguns dos principais estudos publicados no país e no exterior, apontando, sobretudo, a carência de investigações empíricas que identifiquem com precisão os aspectos da forma urbana que podem afetar níveis de poluição atmosférica. Verificaremos ainda os limites dessas abordagens, especialmente em termos de aplicação empírica e precisão nas avaliações das variáveis utilizadas.

Procuraremos responder a essas lacunas através da proposição de uma abordagem analítica panorâmica, ou seja, centrada nas relações gerais entre os principais fatores reconhecidos como tendo potencial explicativo na definição do problema e hipótese. 0 objetivo é reconhecer fatores em jogo na relação entre morfologia urbana e qualidade do ar. Para tanto, faremos uso de métodos estatísticos aplicados em um estudo de caso na cidade do Rio de Janeiro. Veremos que os resultados apontam para graus distintos de influência das variáveis morfológicas selecionadas (TO e VERT) na concentração dos contaminantes analisados (SO2, CO e PI).

\section{Poluição do ar e seus impactos}

A qualidade do ar e a poluição atmosférica são questões relacionadas à intensidade, quantidade e concentração de compostos e partículas na atmosfera. A presença exacerbada de alguns elementos pode 
impactar de modo negativo a saúde, o bem estar público e suas atividades normais, os materiais das edificações, a fauna, a flora e a segurança da propriedade (MMA, 1990). Sendo assim, é comum que os governos monitorem compostos que possam trazer prejuízos. Dentre os controlados no Brasil, abordaremos o monóxido de carbono (CO), o dióxido de enxofre (SO2) e as Partículas Inaláveis (PI).

O CO é um gás produzido principalmente pela combustão dos automóveis ( $90 \%$ das emissões) e sua concentração pode chegar a um nível 100 vezes maior nas cidades do que nas áreas circundantes. Quando inalado em grande quantidade, diminui drasticamente a oxigenação dos órgãos e tecidos, podendo provocar a morte (Castro et al., 2003; Adler \& Tanner, 2015).

O SO2 é um gás produzido naturalmente, mas também pela queima de combustíveis fósseis em indústrias, refino de minérios, poeira da agricultura e pecuária, entre outros (Galloway, 1996). Sua inalação excessiva pode causar irritação da mucosa respiratória, levando à inflamação, hemorragia e necrose, doenças cardíacas e pulmonares (Adler \& Tanner, 2015). A interação do SO2 com outros compostos atmosféricos ainda gera o ácido sulfúrico (H2SO4), componente da chuva ácida, que corrói metais, danifica materiais, tecidos e superfícies.

As Partículas Inaláveis (PI) são poluentes atmosféricos encontrados nos estados sólido e líquido com menos de $10 \mu \mathrm{m}$ (micrómetros) de diâmetro e que, por isso, podem ser inaladas. São provocadas por processos naturais, mas também pela queima de combustíveis fósseis e vegetais em indústrias. Além de reduzir a visibilidade e danificar materiais e construções, as PI aumentam a incidência e a severidade de doenças respiratórias e a mortalidade (Shumway et al., 1988).

Os efeitos desses compostos e outros têm sido sentidos desde a escala local até a global. Isso acontece porque, normalmente ao serem emitidos, os poluentes se misturam com um grande volume de ar (GER), 2015) e a partir daí seu destino e velocidade de dispersão passam a se relacionar com fatores como a topografia local, as condições atmosféricas e meteorológicas, que ajudam a remover e transportar esses poluentes na atmosfera (Frank et al., 2006). As condições meteorológicas são especialmente importantes por modificarem as condições dos ventos, fundamentais na dispersão dos contaminantes, e das chuvas, que ajudam na sua deposição. Nas cidades, onde a emissão de poluentes é associada à densidade populacional, situações meteorológicas desfavoráveis podem provocar ainda mais a concentração de poluentes (Duchiade, 1992) e, por isso, dirigimos nossa atenção a esses ambientes.

\section{Cidade, Clima e Poluição do Ar: O Estado da Arte}

Um dos principais fatores meteorológicos responsáveis pela qualidade do ar nas cidades é a ventilação. Nas áreas urbanas seu padrão natural tende a ser alterado, pois as edificações interferem em sua direção e velocidade média (Landsberg, 1997; Robaa, 2003). Essas alterações tendem a reduzir a transferência térmica das edificações para o meio, dificultando o transporte dos poluentes para fora das áreas urbanas (Adler \& Tanner, 2015).

Essa característica da ventilação nas cidades ainda pode ser agravada quando as situações meteorológicas se encontram desfavoráveis e ocorrem situações de calmaria (Graedel \& Crutzel, 1997) e inversão térmica (Duchiade, 1992), que provocam o conhecido smog (Maia, 2016). Os contaminantes retidos na baixa 
atmosfera podem aderir às superfícies ou ser incorporados à umidade e à chuva. Quando agregados à umidade, são retirados da atmosfera pela ação da gravidade (INEA, 2015). Quando assimilados à precipitação, formam a chuva ácida. Esses fenômenos climáticos naturais podem se intensificar no meio urbano devido, principalmente, à disposição dos edifícios e ao volume de poluentes emitidos nessas áreas.

Há outro fenômeno típico das áreas urbanas: a ilha de calor (Oke, 1987). Duas de suas principais causas são o elevado adensamento construtivo e as atividades produtoras de calor e poluição, como meios de transporte e indústrias. Quando sob as condições desse evento, o ar, muitas vezes, insere-se num ciclo de circulação entre a cidade e a periferia urbana, onde o ar fica aprisionado e a poluição concentrada - chamado domo urbano de poeira (Adler \& Tanner, 2015).

No que se refere à interação desses fenômenos climáticos com os níveis de poluentes e o ambiente urbano, observa-se que, apesar de alguns estudos teóricos sugerirem a influência da forma física urbana no clima e do clima nos níveis poluição, de modo geral, os estudos empíricos disponíveis parecem enfrentar dificuldades em estabelecer a relação de características morfológicas com a poluição de modo direto. Isso pode ser devido à complexidade tanto do tecido morfológico das cidades como dos efeitos que envolvem o clima e a poluição.

Há trabalhos que relacionam a morfologia com o comportamento humano. Um dos pioneiros nesse sentido é o de Newman \& Kenworthy (1989), que relaciona a forma urbana ao uso de combustível fóssil. Recentemente Ewing \& Cevero (2010) e Echenique et al. (2012) apontaram para a redução do uso do automóvel com o aumento da densidade. Correlacionando aspectos da forma urbana e emissões de CO2, Salat (2009) também aponta que a morfologia urbana tem forte potencial para reduzir consumos de energia e as emissões de gases efeito de estufa. Essencialmente, a maioria dos estudos nesse campo relacionam as viagens de automóvel e a matriz energética com os níveis de poluição, mas não incluem poluentes entre suas variáveis empíricas. Ainda, a discussão da forma tende a se focar no nível de compacidade bidimensional do tecido construído, não considerando fatores espaciais com poder explicativo adicional, como o grau de verticalização, o percentual de ocupação do solo, a permeabilidade do tecido urbano ao vento, etc.

Investigações distintas discutem como outros fatores urbanos podem se relacionar com a poluição. São citados fatores como: localização (Lam et al., 1999); proximidade do centro da cidade (Hoek \& Brunekreef, 2002); densidade populacional, tamanho da cidade, topografia, intensidade de atividades humanas, altitude e distância do mar (Givoni, 1998); distância das fontes de poluição, condições de tráfego, características geográficas e de uso do solo (Chan \& Kwok, 2001); densidade da área urbana, tamanho e altura de edifícios, orientação das ruas, variabilidade, tamanho e distribuição de espaços abertos e cinturões verdes (Givoni, 1998). Contudo a maioria desses estudos não aponta conexões de efeito entre aspectos específicos da morfologia urbana e a concentração de poluentes atmosféricos. Vemos ainda uma significativa escassez de evidências empíricas consistentes dessas conexões.

Um exemplo dessa tendência é encontrado em Adolphe (2001), que considera adequadamente que diferentes configurações da forma urbana sejam capazes de alterar fluxos relacionados ao clima, alterando o microclima interno e externo às edificações. Considera ainda que cada configuração modificaria esses fluxos de maneira diferente - mas o autor não realiza avaliação classificatória capaz de reconhecer diferentes desempenhos de diferentes configurações, nem o quanto cada aspecto da forma poderia importar. 
Outros trabalhos trazem aproximações empíricas mais consistentes. Netto et al. (2012; 2019) revelaram uma associação estatística entre uso pedestre e tipos arquitetônicos em três capitais brasileiras, apontando para a forma urbana contínua e compacta como associada positivamente ao movimento de pedestres. Usando outro método, o estudo de Larrañaga et al. (2009) mostra que o alto número de deslocamentos a pé se relaciona à dificuldade de utilizar modos de transporte ativo. Similarmente Frank et al. (2006) buscam associações entre a facilidade que o bairro oferece para viagens a pé (caminhabilidade) e a qualidade do ar. Através de modelos de regressões lineares encontraram que a caminhabilidade impacta as distâncias viajadas por veículo e explica a variabilidade de parte das emissões de Óxidos de Nitrogênio (NOx) e Compostos Orgânicos Voláteis (COV). Em pesquisas anteriores, os autores já haviam encontrado correlações positivas entre distâncias viajadas de veículo per capita e emissões per capita de NOx e COV (Frank at al., 2000); bem como correlações negativas entre o uso misto do solo, densidades altas e maior conectividade de ruas com emissões de NOx e COV (Frank \& Engelke, 2005; Frank et al., 2000; Frumkin et al., 2004). Essas associações sugerem uma relação entre padrões da morfologia e indução à dependência veicular, fatores geradores de emissões de COV e NOX.

Essas pesquisas não relacionam aspectos da forma com a poluição diretamente. Entretanto Pan et al. (2010) desenvolveram um estudo estatístico visando investigar a influência de variáveis meteorológicas e

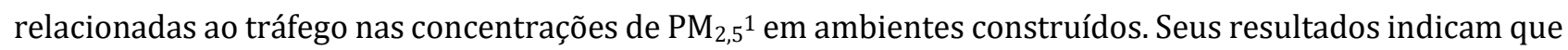
a altura das edificações pode influenciar na velocidade do vento e, consequentemente, na dispersão dos poluentes no tecido urbano. Apesar de esse estudo ter considerado a influência da morfologia na dispersão dos poluentes, não incluiu variáveis morfológicas entre as variáveis preditivas da poluição.

Uma exceção na literatura quanto ao tratamento analítico e empírico preciso de fatores espaciais urbanos e poluentes é encontrada em Edussuriya (2006). 0 autor desenvolve um estudo estatístico onde analisa as relações entre aspectos da morfologia urbana (altura média e distância entre edifícios, usos do solo, compacidade, rugosidade ${ }^{2}$, configuração das edificações e ruas, etc.) e a concentração de poluentes aéreos (PM2.5, NOX, O3³ e CO), incluindo parâmetros climatológicos (temperatura, umidade relativa do ar, direção e velocidade do vento) e de tráfego (quilometragem viajada/veículo, densidade de veículos e fluxo de tráfego). Seus resultados apontam correlações significativas entre variáveis morfológicas associadas à rugosidade e a compacidade 2D e 3D e a concentração de poluição no nível da rua.

Poucos estudos no contexto internacional e nacional têm trazido evidências sobre a relação entre morfologia urbana e a concentração de poluentes aéreos. 0 estado da arte no campo sugere que ainda há muito a ser explorado - especialmente no que se refere à influência de diferentes aspectos morfológicos e a tratamentos empíricos precisos das interações da forma urbana e qualidade do ar. Vejamos a seguir como essa tem sido tratada na Cidade do Rio de Janeiro (CRJ).

\footnotetext{
${ }^{1}$ PM2,5 são partículas inaláveis com diâmetro menor que 2,5 $\mu \mathrm{m}$.

${ }^{2}$ Rugosidade se refere ao número de obstáculos que afetam o fluxo de vento (Adolphe, 2001).

${ }^{3}$ Ozônio.
} 


\section{Fatores de Qualidade do Ar na cidade do Rio de Janeiro}

No Rio de Janeiro três órgãos públicos dispõem de uma rede de estações meteorológicas que incluem aferição de poluentes e ajudam a fazer o controle e a classificação da qualidade do ar na cidade: Instituto Estadual do Ambiente (INEA), Secretaria Municipal de Meio Ambiente (SMAC) e Instituto Nacional de Meteorologia (INMET).

Um dos instrumentos que auxilia esses órgãos a fazer o monitoramento é o inventário de fontes de emissão de poluição atmosférica feito em 2004 pela Fundação Estadual de Engenharia do Meio Ambiente (FEEMA) para a Região Metropolitana do Rio de Janeiro (RMRJ). Ele identificou que as fontes fixas de poluição (indústrias) são responsáveis especialmente pela emissão de SO2 (88\%). Já as fontes móveis (veículos automotores) contribuem, principalmente, com as emissões de NOx (67\%), CO (98\%) e hidrocarbonetos (HC - 67\%). Em relação às PI (MP10), há uma contribuição mais equilibrada das fontes fixas e móveis.

A análise da literatura evidencia uma carência de estudos relativos à climatologia urbana que subsidiem os estudos de qualidade do ar na CRJ. Os autores que tratam do tema tendem a destacar o relevo acidentado e sua influência na climatologia criando divisores microclimáticos e dificultando a atuação dos ventos. Ainda ressaltam que devem ser ponderadas as características do clima tropical onde a região se insere, com intensa radiação solar e temperaturas elevadas (Carvalho et al., 2002), que favorecem a ocorrência de fenômenos associados à temperatura como a ilha de calor e o domo urbano de poeira. De modo geral, os estudos parecem se concentrar no regime de ventos e nas influências do relevo, como é o caso das investigações de Pimentel et al. (2014) e Farias (2013).

Durante o período de pesquisa foi possível identificar apenas dois estudos para além desse caráter. Barbosa et al. (2014) estudaram a relação do clima com as mudanças da morfologia e da tipologia no bairro de Copacabana ao longo do séc. XX, demonstrando como as alterações trouxeram consequências climáticas diretas no ambiente, causando aumento considerável da temperatura e alteração nos fluxos de ventilação. Os autores se referem a impactos desses fatores na poluição, mas não apresentam estudo empírico sobre o assunto. Albuquerque (2014) analisou a influência da morfologia urbana e das diferentes formas de ocupação do solo no comportamento microclimático. Ela encontrou relações entre áreas com os maiores índices construtivos e/ou com menores percentuais de cobertura vegetal e suas temperaturas e umidade relativa. Não obstante, a autora não faz associações desses achados com a poluição atmosférica.

Tendo identificado a insuficiência de estudos que tratem empiricamente das interações da forma urbana com a qualidade do ar, tanto no contexto internacional quanto no Brasil e na CRJ, propomos um tratamento alternativo a essa questão.

\section{Fatores Urbanos e Ambientais: Abordagem e Método}

Dispomo-nos a investigar se diferenças morfológicas associadas à Taxa de Ocupação (T0) e ao percentual de verticalização arquitetônica (VERT) em quadras urbanas podem impactar a concentração de poluentes atmosféricos, mais precisamente, a concentração de CO, SO2 e PI. Baseados na bibliografia do tema, sugerimos que esse impacto exista e que possa se dar tanto através da interferência da morfologia em (i) fatores 
comportamentais humanos, como a intensidade de uso de automóveis particulares, quanto em (ii) vetores ambientais, como a temperatura, os regimes de chuvas e ventos que, associados à posição geográfica em relação ao relevo e à hidrografia, poderão impactar (iii) a concentração de poluentes no ar (Figura 1).

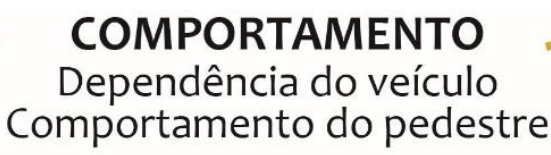

MORFOLOGIA

Taxa de Ocupação

Taxa de Verticalidade
QUALIDADE DO AR $\mathrm{SO} 2, \mathrm{CO}$ e $\mathrm{PI}$

\section{FATORES AMBIENTAIS}

Chuva, Ventos e Temperatura

\footnotetext{
Figura 1 - Hipótese das relações de efeitos possíveis entre fatores espaciais, comportamentais, ambientais e a qualidade do ar selecionados

Fonte: Elaborado pelos autores.
}

Selecionamos esses fatores como tendo potencial explicativo sobre a qualidade do ar, mas, naturalmente, consideramos que outros não apontados possam estar ativos. Isso é devido à natureza do problema de pesquisa envolvendo sistemas complexos (urbano, ecossistêmico, atmosférico) e, portanto, abertos, abrangendo multiplicidades de variáveis e não linearidades em seu comportamento. Dessa forma, é esperado que variáveis não consideradas neste estudo possam interferir nas relações em jogo. Seu exame requer outras formas de modelagem e tipos de dados, os quais escapam a presente abordagem e suas fontes empíricas.

Para responder a essa questão selecionamos a CRJ como estudo de caso. Com base no inventário da FEEMA (2004), elegemos os poluentes a serem analisados: SO2, como indicador das fontes fixas; CO, para refletir as fontes móveis; e as PI, como um poluente não gasoso e proxy dos dois. Também incluímos variáveis meteorológicas (direção e velocidade do vento, precipitação pluvial e temperatura do ar) dadas às suas reconhecidas influências na qualidade do ar. Já TO e VERT são variáveis morfológicas respectivamente associadas à rugosidade e à compacidade 2D e 3D (Maia \& Netto, 2016), aspectos morfológicos apontados pelas pesquisas de Edussuriya (2006) e Pan et al. (2010) como relevantes na concentração dos poluentes.

Tendo como base a literatura pregressa, optamos pela utilização de método quantitativo, realizando exames estatísticos de dois tipos: Correlação de Pearson, para identificar a existência de relação entre os fatores; e Regressão Múltipla, capaz de identificar um possível impacto das variáveis morfológicas e ambientais na concentração dos poluentes.

Através desse método também consideramos a possibilidade de contribuir para o quadro de indicadores que permitam dar novos rumos e prover subsídios à formulação e práticas de políticas públicas no Brasil. Como apontado por Martins \& Cândido (2015), indicadores auxiliam na visualização e no monitoramento do quadro atual de uma sociedade e possibilitam medir a distância de onde se está e para onde se deseja ir. Nota- 
se, no entanto que, no Brasil, os indicadores são pouco explorados no campo de atuação dessa pesquisa e que, muitas vezes, o assunto é abordado de forma teórica, sem aplicação empírica, como propomos aqui.

Os dados ambientais foram disponibilizados pela SMAC e pelo INEA. Essas informações, coletadas por estações meteorológicas localizadas em diferentes áreas da cidade, foram compiladas pela presente pesquisa e organizadas em uma base de dados ambientais na forma de uma série histórica. Foram selecionados os anos de 2012, 2013 e 2014 para os quais havia a maior quantidade de estações com dados disponíveis para análise.

Fizemos análises considerando cada ano em separado e, depois, os três anos de maneira conjunta. Para essa última foi feito um estudo com dados empilhados como se fosse uma nova amostra. Utilizamos ao todo 11 estações (Figura 2), mas como a disponibilidade de dados não era homogênea, cada análise de modo individual contou com 6 estações dentre essas. Tendo trabalhado com valores mensais médios para cada variável, perfizeram um total de 72 observações em cada análise.

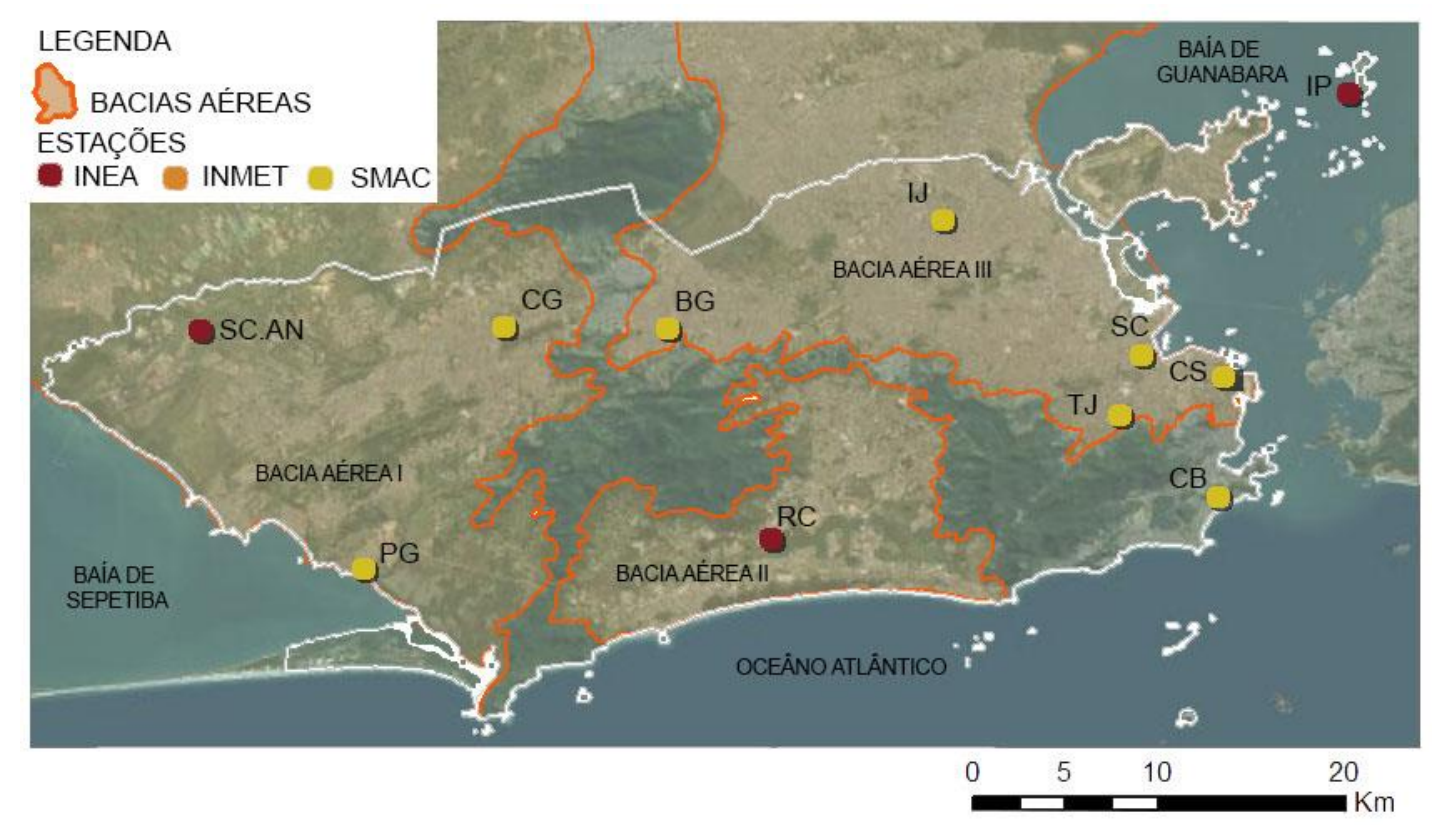

Figura 2 - Localização das 11 Estações Meteorológicas analisadas

Legenda: BG - Bangu | CG - Campo Grande | CS - Centro | CB - Copacabana | IP - Iha de Paquetá | IJ - Irajá | PG - Pedra de Guaratiba | RC - Recreio | SC.AN - Santa Cruz - Adalgisa Neri | SC - São Cristóvão | TJ - Tijuca.

Fonte: Elaborado pelos autores com base em imagem do Google Earth (2013), dados do INEA e da SMAC.

Para a coleta dos dados morfológicos utilizamos o banco de dados do Grupo SEL-RJ (ver Tângari et al., 2011), que oferece informações para todas as quadras da cidade a respeito do percentual de verticalização $e$ de espaços livres (públicos e privados). A VERT refere-se à percentagem de lotes que contenham edificações com quatro pavimentos ou mais e foi medida em três grupos (0-10\%; 10-50\%; mais de 50\%). Observa-se aqui que essa taxa não permite distinguir o desempenho de tipos arquitetônicos: uma torre de 10 andares na Barra da Tijuca, por exemplo, entra na mesma categoria que um edifício construído junto às divisas de 10 andares em Copacabana. Essa é uma questão relevante, porque a diferença tipológica pode ter implicações para efeito de ventilação sobre as variáveis analisadas. Já a incidência percentual de espaços livres aferiu a 
percentagem de espaços livres existentes em relação à área ocupada por lote e também a partir de três grupos percentuais (0-30\%; 30-50\%; mais de 50\%). Essa última nos permitiu calcular a TO das quadras.

Observamos que a natureza dessa classificação, em percentagem e dividida em apenas três grupos, envolveu uma definição a priori, i.e. que não emergiu de uma análise de distribuições das características morfológicas, não sendo portanto uma medida tão precisa quanto desejável. Entretanto sua relevância se deve à extensão do banco de dados que cobre a totalidade da área da cidade e viabiliza a análise estatística de todas as estações. Como VERT não define acuradamente a altura das edificações, utilizamos essa variável como um indicador da rugosidade do tecido urbano, considerando que morfologias com maior percentual de verticalização oferecerão possivelmente mais obstáculos ao vento. Já a TO foi usada como proxy da compacidade do tecido, visando verificar a possibilidade de formas mais compactas promoverem maior aprisionamento de poluentes, ou de menor emissão, no caso de promoverem redução de viagens veiculares.

Utilizando a localização espacial das estações meteorológicas, as áreas para análise foram definidas em recortes de 500 x 500 m no entorno das estações (Figura 3).

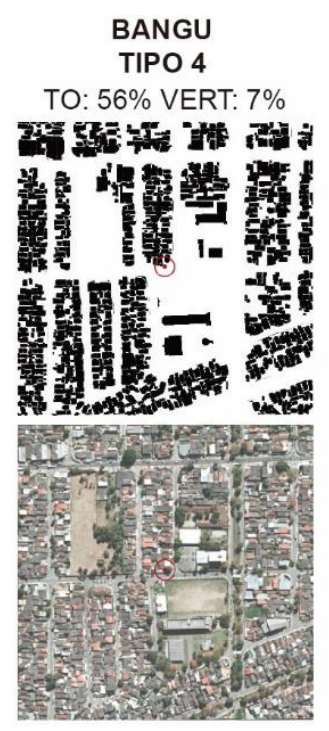

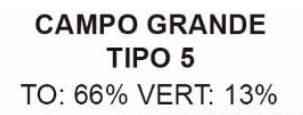
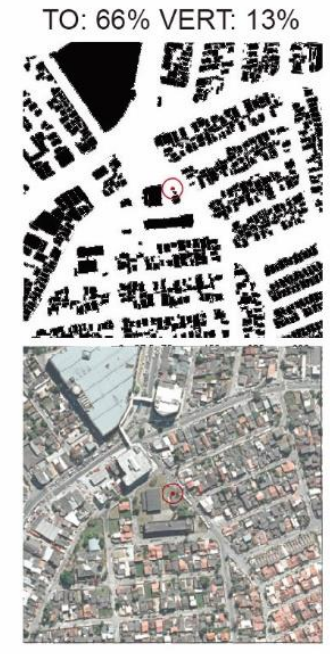
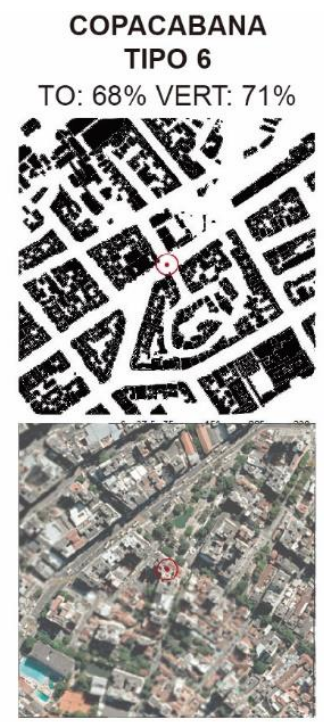

\section{P. DE GUARATIBA}

TIPO 7

TO: $37 \%$ VERT: $5 \%$
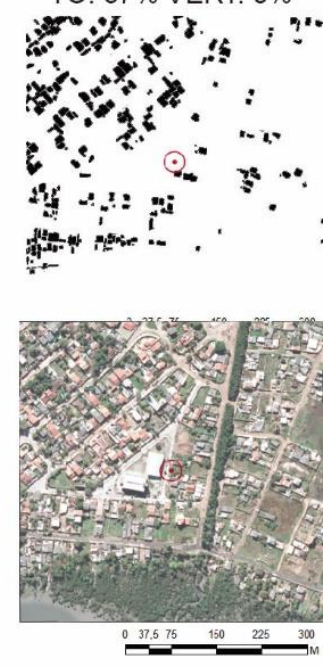

Figura 3 - Exemplo das principais janelas morfológicas no entorno das estações Meteorológicas analisadas Fonte: Elaborado pelos autores com base em imagem do Google Earth (2013).

Cientes da importância do clima para a qualidade do ar, apresentamos uma análise simplificada dos anos estudados numa comparação das médias mensais de temperatura, precipitação média acumulada e intensidade do vento entre si e em relação às normais climatológicas da CRJ (Erro! Fonte de referência não encontrada.). Para que as análises em relação às normais (fornecidas somente pelo INMET) pudessem ser coerentes, utilizamos todos os dados da Estação Rio de Janeiro do INMET para a construção desse gráfico.

A temperatura do ar média dos 3 anos estudados (Gráfico 1) indica um comportamento similar entre eles e, em todos os casos, acima do esperado (de $1,1^{\circ} \mathrm{C}$ a $2,5^{\circ} \mathrm{C}$ para mais). $\mathrm{Na}$ escala mensal o comportamento desse elemento, em relação à normal, apresentou anomalias, tendo tido mais regularidade no que se refere ao comportamento anual. As médias anuais foram mais parecidas nos anos de $2012\left(25,39^{\circ} \mathrm{C}\right)$ e 2014 $\left(25,36^{\circ} \mathrm{C}\right)$, tendo sido $2013 \mathrm{um}$ ano de temperatura mais amena $\left(24,9^{\circ} \mathrm{C}\right)$. 


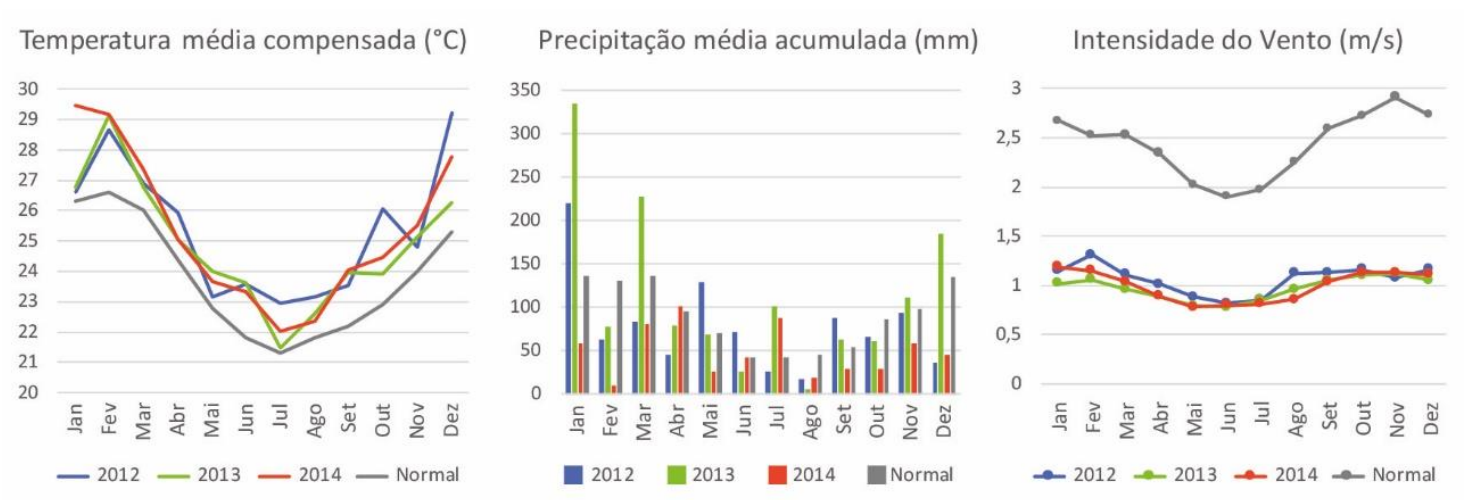

Gráfico 1 - Temperaturas médias compensadas $\left({ }^{\circ} \mathrm{C}\right)$, precipitação média acumulada $(\mathrm{mm})$ e intensidade do vento $(\mathrm{m} / \mathrm{s})$ : comparação 2012-2014

Fonte: Elaborado pelos autores a partir de dados do INMET.

O confronto da precipitação pluvial acumulada mostra que os anos foram atípicos, com distribuição da curva pluviométrica bastante alternada. Isso se deve a influência de sistemas produtores de chuva de característica regional e local que atuam na CRJ. Os anos de 2014 e 2012 foram secos (INMET, 2015), tendo sido o primeiro o mais seco (585 mm anual), seguido pelo segundo (941,1 mm anual). Em 2013, por outro lado, choveu acima do esperado (1341 mm anual - $272 \mathrm{~mm}$ a mais), mas ainda assim foi considerado um ano normal (INMET, 2015).

A análise da intensidade do vento revelou que todos os anos obtiveram velocidades abaixo do esperado (menos de 50\%), tendo o ano de 2012 apresentado a maior intensidade (média de 1,07m/s), seguido de 2014 (média de 0,99m/s) e 2013 (média de 0,97m/s).

\section{Morfologia urbana e polvição do ar: Análises Estatísticas}

As primeiras análises apresentadas são as correlações de Pearson. Estas medem o grau da correlação entre duas variáveis de escala métrica. Seus resultados variam entre -1 (correlação negativa perfeita, indicando comportamentos reversos entre variáveis), zero (denotando ausência de correlação linear) e +1 (correlação positiva perfeita, indicando comportamentos equivalentes entre variáveis). Esses números são associados a "p-valores" que, quando menores que 0,1 , indicam que existe correlação estatisticamente significativa.

Ressaltamos aqui que esse estudo envolve relações entre dois sistemas complexos: a cidade em sua morfologia e componentes ecossistêmicos atmosféricos. Estes são sistemas por definição "complexos" (McPhearson et al., 2016), i.e. abertos, envolvendo multiplicidade de componentes e imprevisibilidade de comportamento, com possibilidade de presença de variáveis e contingências não modeladas ou identificadas empiricamente, que podem interferir nas relações entre os fatores conhecidos, adicionando não linearidade e ruído. Nesses sistemas, a detecção de graus altos de correlação estatística entre o comportamento de componentes distintos se torna menos provável. Assim, devemos ficar atentos mesmo a valores de correlação aparentemente modestos como possíveis indícios das relações de implicação e efeito entre variáveis, em relações bivariadas. 
As análises de correlação para os anos de 2012, 2013 e 2014 (Tabelas 1, 2 e 3) revelaram o grau de coincidência entre parâmetros morfológicos e a concentração dos poluentes para os casos estudados.

Tabela 1 - Análises de Correlação de Pearson 2012.

\begin{tabular}{cccc}
\hline 2012 & $\mathrm{SO}_{2}$ & $\mathrm{CO}$ & $\mathrm{PI}$ \\
\hline CHUVA & $-0,31^{* *}$ & 0,08 & $-0,16$ \\
TEMP & $0,32^{* *}$ & $-0,27^{*}$ & $-0,13$ \\
T.O. & $-0,39 * *$ & $-0,04$ & $0,25^{*}$ \\
VERT & 0,00 & $-0,11$ & $0,29^{*}$ \\
& P-valores: $<0.1 ; * 0.05 ; *<0.01$. &
\end{tabular}

Fonte: Elaborado pelos autores a partir de dados do INMET e SMAC.

Tabela 2 - Análises de Correlação de Pearson 2013.

\begin{tabular}{cccc}
\hline 2013 & $\mathrm{SO}_{2}$ & $\mathrm{CO}$ & $\mathrm{PI}$ \\
\hline CHUVA & $-0,26^{*}$ & $-0,16$ & $-0,45^{* *}$ \\
TEMP & 0,08 & $-0,07$ & $-0,15$ \\
T.O. & $-0,44^{* *}$ & $-0,11$ & 0,12 \\
VERT & $-0,06$ & $0,25^{*}$ & 0,21
\end{tabular}

Fonte: Elaborado pelos autores a partir de dados do INMET e SMAC.

Tabela 3 - Análises de Correlação de Pearson 2014.

\begin{tabular}{cccc}
\hline 2013 & SO2 & CO & PI \\
\hline CHUVA & $-0,26^{*}$ & $-0,16$ & $-0,45^{* *}$ \\
TEMP & 0,08 & $-0,07$ & $-0,15$ \\
T.O. & $-0,44^{* *}$ & $-0,11$ & 0,12 \\
VERT & $-0,06$ & $0,25^{*}$ & 0,21 \\
& \multicolumn{2}{c}{ P-valores: $<0.1 ; *<0.05 ; *<0.01}$. &
\end{tabular}

Fonte: Elaborado pelos autores a partir de dados do INMET e SMAC.

Considerando variáveis morfológicas e poluentes, as correlações mais consistentes foram encontradas entre a Taxa de Ocupação (TO) e o dióxido de enxofre (SO2) de uma correlação negativa fraca em 2012 (0,39), moderada em $2013(-0,44)$ à forte em $2014(-0,77)$. Tendo em vista a natureza de suas fontes emissoras, sugerimos que a associação do aumento da concentração de SO2 com áreas menos ocupadas seja reflexo da localização predominante das indústrias em locais menos edificados da cidade.

Já as Partículas Inaláveis (PI) e TO apresentaram correlação positiva fraca em $2012(0,25)$ e $2014(0,20)$ e bem fraca em $2013(0,12)$. Apesar das relações terem sido baixas, o resultado aponta um incremento do poluente em áreas mais ocupadas. Isso indica, possivelmente, uma dificuldade de dispersão do PI em lugares onde o aglutinamento das edificações pode afetar a ventilação. A correlação mais fraca de 2013 pode ser explicada pelo índice pluviométrico do ano, que foi o maior dos três: o aumento do volume de chuvas pode ter favorecido a deposição do poluente nesse ano, o que se verifica na correlação moderada negativa de PI com a Chuva $(-0,45)$.

Dentre os poluentes considerados, as correlações mais fracas de TO foram com o monóxido de carbono (CO). Os resultados apontaram para a quase ausência de relação linear em $2012(-0,04)$ e $2014(0,07)$ e uma 
relação negativa muito fraca no ano de $2013(-0,11)$. Esses resultados apontam para a necessidade de investigações mais detalhadas a respeito desse poluente.

Observando as análises para Percentual de Verticalização (VERT), notamos que a correlação mais consistente foi encontrada com PI: positiva fraca, mas ainda assim mostrando a importância da variável morfológica na concentração do poluente: 0,29 para 2012; 0,21 para 2013; e 0,34 para 2014. Essa associação entre VERT e intensidade desse poluente sugere a possibilidade das morfologias mais verticalizadas estarem dificultando os movimentos de ar que ajudariam na dispersão de PI. Essa suposição pode ser endossada não só pela literatura (Pan et al., 2010; Landsberg, 1997; Robaa, 2003), mas também pela análise de 2014, que considerou a variável ventilação, tendo sua velocidade apresentado correlações negativas fortes com a verticalização $(-0,72,-0,69$ e -0,72; dados fora da Tabela 3).

O Monóxido de Carbono (CO), por outro lado, apresentou correlações negativas com o VERT em 2012 ($0,11)$ e $2014(-0,20)$. Ao ponderar a natureza das fontes emissoras do CO, a tendência geral sugere a possibilidade das morfologias mais verticalizadas estarem associadas a um menor uso de automóvel. 0 poluente, no entanto, apresentou uma reversão positiva de intensidade similar em $2013(0,25)$. Essa alteração em relação aos anos anteriores indica interferência e demanda acompanhamento via dados dos anos seguintes, de 2015 em diante, indisponíveis nesse momento da pesquisa.

As correlações mais fracas desse parâmetro foram encontradas com SO2, tendo apresentado correlação negativa fraca em $2014(-0,14)$ e quase ausência de relação linear em $2012(0,00)$ e $2013(-0,06)$.

Em relação aos parâmetros ambientais, foi identificada uma correlação negativa dos poluentes com a precipitação pluvial (chuva) em todos os anos. Ou seja, o aumento da precipitação pode ser associado à redução dos contaminantes. Esse achado confirma o entendimento da atuação da chuva como agente de deposição dos poluentes, como apontado pela literatura. Essa correlação, porém, não foi forte, possivelmente devido ao índice pluviométrico não ter sido muito alto nos anos analisados.

A temperatura, por outro lado, apresentou diferentes relações com os poluentes em cada ano. Em 2012, a intensificação desta variável ambiental foi associada à redução dos poluentes CO $(-0,27)$ e PI $(-0,13)$ e a um incremento de SO2 $(0,32)$. A correlação negativa com os dois primeiros poluentes pode indicar que a temperatura tenha favorecido os movimentos de ar ascendentes que ajudam na dispersão dos poluentes em áreas mais ocupadas, onde predominantemente se encontram as fontes desses poluentes (veículos e construção civil). Já a correlação positiva com SO2 pode significar que, nas áreas menos ocupadas, onde se concentram suas principais fontes (indústrias), a temperatura tenha auxiliado na criação de um domo de poeira que teria aprisionado o contaminante, desse modo, aumentando a sua concentração. Em 2013 observamos novamente o impacto da temperatura na redução de PI $(-0,15)$, mas a variável não parece ter tido relação linear com a concentração dos outros poluentes, como revelado por suas correlações muito fracas - SO2 $(0,07)$ e CO $(-0,08)$. Em 2014 a temperatura não mostrou relação linear considerável com nenhum dos três poluentes - SO2 $(-0,01)$, CO $(-0,07)$ e PI $(-0,08)$. Essa ausência de relação do poluente com a temperatura contradiz achados anteriores na literatura, especialmente considerando que esses foram anos mais quentes do que a normal. Porém a falta de consistência no resultado entre os anos sugere a necessidade de investigações mais detalhadas que, entre outros fatores, possa ampliar a série histórica. 
Finalmente, a velocidade e direção dos ventos só puderam ser analisadas para o ano de 2014, para o qual havia disponibilidade do dado. Pudemos observar a redução dos contaminantes com o aumento da velocidade do vento - SO2 $(-0,34)$ e PI $(-0,29)$-, confirmando seu papel na dispersão dos contaminantes, como indicado na bibliografia. Por outro lado, a associação de sua direção com o aumento de SO2 $(0,21)$ indica um possível aporte do poluente de outras áreas. 0 elemento climático, entretanto, não apresentou relações consideráveis com CO $(-0,05$ e $-0,09)$.

\section{Análises de regressão múltipla}

A regressão múltipla foi a segunda técnica estatística utilizada, ela envolve a construção de modelos que descrevem relações entre diversas variáveis ao mesmo tempo, com potencial explicativo sobre o comportamento de um processo, i.e. permitindo prever os valores da variável dependente com base no relacionamento conhecido que existe entre ela e as variáveis independentes. Utilizamos, inicialmente, um modelo de regressão stepwise, que nos permitiu selecionar cada variável a ser utilizada em cada modelo. Depois, utilizamos o modelo de regressão múltipla simples na base logarítmica apresentado a seguir.

Nossas análises de regressão (Tabelas 4, 5 e 6) confirmam o papel explicativo dos parâmetros morfológicos na variação da concentração dos poluentes nos anos estudados. A T0 só não pôde ser envolvida na explicação da variação de PI em 2014 e a VERT só não ajudou a explicar a variação de SO2 em 2013.

As regressões de 2012 (Tabela 4) afirmaram o poder explicativo da temperatura para os três contaminantes, sendo o seu aumento associado ao incremento de $\mathrm{SO} 2$ e a uma redução de CO e PI. Os modelos foram capazes de explicar $50 \%$ da concentração de SO2, 12,8\% da concentração de CO e 10,3\% da concentração de PI.

Tabela 1 - Análises descritivas e de Regressão 2012

\begin{tabular}{|c|c|c|c|c|c|c|c|c|c|}
\hline 2012 & \multicolumn{9}{|c|}{ Análises Descritivas } \\
\hline Polventes & \multicolumn{3}{|c|}{ SO2 } & \multicolumn{3}{|c|}{$\mathrm{CO}$} & \multicolumn{3}{|c|}{ PI } \\
\hline Mediana & \multicolumn{3}{|c|}{4,381} & \multicolumn{3}{|c|}{0,386} & \multicolumn{3}{|c|}{33,7} \\
\hline Média & \multicolumn{3}{|c|}{5,354} & \multicolumn{3}{|c|}{0,3993} & \multicolumn{3}{|c|}{35,2} \\
\hline Desvio & \multicolumn{3}{|c|}{3,736} & \multicolumn{3}{|c|}{0,1381} & \multicolumn{3}{|c|}{7,865} \\
\hline \multirow[t]{2}{*}{$\begin{array}{l}\text { Coef. de } \\
\text { variação }\end{array}$} & \multicolumn{3}{|c|}{1,433} & \multicolumn{3}{|c|}{2,892} & \multicolumn{3}{|c|}{4,476} \\
\hline & \multicolumn{9}{|c|}{ Análises de Regressão } \\
\hline \multirow{2}{*}{2012} & \multicolumn{3}{|c|}{$\mathrm{SO}_{2}\left[\mathrm{R}^{2} 50,0 \%\right]$} & \multicolumn{3}{|c|}{ CO [R2 12,8\%] } & \multicolumn{3}{|c|}{$P I\left[R^{2}\right.$ 10,3\%] } \\
\hline & Coef. & $\begin{array}{c}\text { Erro } \\
\text { Padrão }\end{array}$ & $\operatorname{Pr}(>|t|)$ & Coef. & $\begin{array}{c}\text { Erro } \\
\text { Padrão }\end{array}$ & $\operatorname{Pr}(>|t|)$ & Coef. & $\begin{array}{c}\text { Erro } \\
\text { Padrão }\end{array}$ & $\operatorname{Pr}(>|t|)$ \\
\hline CHUVA & -2.951 & 3,482 & 0,3998 & $\begin{array}{c}0,04618 \\
-\end{array}$ & 0,17005 & 0,7868 & $-0,048$ & 0,0352 & 0,18 \\
\hline TEMP & 0,377 & 0,124 & 0,0034 & 0,01736 & 0,00607 & $5,60 \mathrm{E}-03$ & $\begin{array}{c}-0,203 \\
-\end{array}$ & 0,2515 & 0,42 \\
\hline TO & $-1,862$ & 0,297 & $3,00 \mathrm{E}-08$ & $\begin{array}{c}0,00396 \\
-\end{array}$ & 0,01451 & 0,7859 & 0,0471 & 0,2565 & 0,85 \\
\hline VERT & 1,133 & 0,203 & $4,80 \mathrm{E}-07$ & 0,01348 & 0,00993 & $1,79 \mathrm{E}-01$ & 0,101 & 0,1196 & 0,4 \\
\hline
\end{tabular}


(Conclusão)

\begin{tabular}{|c|c|c|c|c|c|c|c|c|c|}
\hline \multirow[b]{2}{*}{ TesteF } & \multicolumn{9}{|c|}{ Análises dos resíduos } \\
\hline & 16,8 & - & $1,42 \mathrm{E}-09$ & 2,45 & - & 0,0544 & 1,93 & - & 0,115 \\
\hline Outlier Test & 2,57 & - & 0,012 & 3,19 & - & 0,002 & 2,73 & - & 0,007 \\
\hline $\begin{array}{l}\text { Shapiro-Wilk } \\
\text { (Normalidade) }\end{array}$ & 0,99 & - & 0,875 & 0,97 & - & 0,231 & 0,99 & - & 0,885 \\
\hline
\end{tabular}

Para 2013 os dados (Tabela 5) indicaram que, dentro dos parâmetros morfológicos selecionados, a verticalização só não foi capaz de explicar a variação de SO2. A precipitação pluvial foi a principal variável na explicação da variação de PI e a taxa de ocupação e a temperatura foram as mais relevantes na variação de SO2, tendo sido a segunda mais relevante. A taxa de ocupação ainda aparece como a variável de mais peso na explicação da variação de CO. Os modelos foram capazes de explicar $21,5 \%$ da concentração de SO2, 21,3\% da concentração de CO e $24,0 \%$ da concentração de PI.

Tabela 2 - Análises descritivas e de Regressão 2013

\begin{tabular}{|c|c|c|c|c|c|c|c|c|c|}
\hline 2013 & \multicolumn{9}{|c|}{ Análises Descritivas } \\
\hline Polventes & \multicolumn{3}{|c|}{$\mathrm{SO} 2$} & \multicolumn{3}{|c|}{$\mathrm{CO}$} & \multicolumn{3}{|c|}{ PI } \\
\hline Mediana & \multicolumn{3}{|c|}{2,632} & \multicolumn{3}{|c|}{0,374} & \multicolumn{3}{|c|}{29,4} \\
\hline Média & \multicolumn{3}{|c|}{3,685} & \multicolumn{3}{|c|}{0,423} & \multicolumn{3}{|c|}{30,6} \\
\hline Desvio & \multicolumn{3}{|c|}{2,962} & \multicolumn{3}{|c|}{0,2105} & \multicolumn{3}{|c|}{6,753} \\
\hline \multirow[t]{2}{*}{$\begin{array}{l}\text { Coef. de } \\
\text { variação }\end{array}$} & \multicolumn{3}{|c|}{1,244} & \multicolumn{3}{|c|}{2,01} & \multicolumn{3}{|c|}{4,532} \\
\hline & \multicolumn{9}{|c|}{ Análises de Regressão } \\
\hline \multirow[t]{2}{*}{2013} & \multicolumn{3}{|c|}{$\mathrm{SO}_{2}-\mathrm{R}^{2} 21,5 \%$} & \multicolumn{3}{|c|}{$C O-R^{2} 21,3 \%$} & \multicolumn{3}{|c|}{$P I-R^{2} 24,0 \%$} \\
\hline & Coef. & $\begin{array}{c}\text { Erro } \\
\text { Padrão }\end{array}$ & $\operatorname{Pr}(>|\dagger|)$ & Coef. & $\begin{array}{c}\text { Erro } \\
\text { Padrão }\end{array}$ & $\operatorname{Pr}(>|t|)$ & Coef. & $\begin{array}{c}\text { Erro } \\
\text { Padrão }\end{array}$ & $\operatorname{Pr}(>|\dagger|)$ \\
\hline CHUVA & $-0,1267$ & 0,0714 & 0,08067 & 0,00133 & 0,0492 & 0,9785 & 24.848 & 5.885 & $7,70 \mathrm{E}-05$ \\
\hline TEMP & $-1,3910$ & 1,0088 & 0,17252 & $-0,2408$ & 0,6505 & 0,7125 & 0,229 & 0,333 & 0,495 \\
\hline TO & $-1,2649$ & 0,3654 & 0,00094 & $-1,7638$ & 0,4402 & 0,0002 & 1.047 & 0,65 & 0,112 \\
\hline \multirow[t]{2}{*}{ VERT } & - & - & - & 0,77077 & 0,2033 & 0,0003 & $-0,5$ & 0,48 & 0,301 \\
\hline & \multicolumn{9}{|c|}{ Análises dos resíduos } \\
\hline TesteF & 6,1 & - & 0,000983 & 4,53 & - & 0,0026 & 5,13 & - & 0,001 \\
\hline Outlier Test & 2,1 & - & 0,038 & $-2,31$ & - & 0,023 & 2,16 & - & 0,034 \\
\hline $\begin{array}{l}\text { Shapiro-Wilk } \\
\text { (Normalidade) }\end{array}$ & 0,97 & - & 0,14 & 0,92 & - & 0,0004 & 0,97 & - & 0,199 \\
\hline
\end{tabular}

Fonte: Elaborado pelos autores a partir de dados do INMET e SMAC.

Nas análises para 2014 (Tabela 6) todos os parâmetros se mostram importantes para explicar algum dos poluentes. A direção do vento só não contribuiu na explicação da concentração de SO2 e a taxa de ocupação na da concentração de PI. Os modelos puderam explicar 62,1\% da concentração de SO2, 56,2\% da variação de CO e 16,2\% da concentração de PI. 
Tabela 3 - Análises descritivas e de Regressão 2014

\begin{tabular}{|c|c|c|c|c|c|c|c|c|c|}
\hline 2014 & \multicolumn{9}{|c|}{ Análises Descritivas } \\
\hline Polventes & \multicolumn{3}{|c|}{ SO2 } & \multicolumn{3}{|c|}{ CO } & \multicolumn{3}{|c|}{ PI } \\
\hline Mediana & \multicolumn{3}{|c|}{3} & \multicolumn{3}{|c|}{0,376} & \multicolumn{3}{|c|}{37,9} \\
\hline Média & \multicolumn{3}{|c|}{3,368} & \multicolumn{3}{|c|}{0,362} & \multicolumn{3}{|c|}{39,6} \\
\hline Desvio & \multicolumn{3}{|c|}{2.025} & \multicolumn{3}{|c|}{0,112} & \multicolumn{3}{|c|}{10,7} \\
\hline \multirow[t]{3}{*}{$\begin{array}{l}\text { Coef. de } \\
\text { variação }\end{array}$} & \multicolumn{3}{|c|}{1648} & \multicolumn{3}{|c|}{3,232} & \multicolumn{3}{|c|}{3,934} \\
\hline & \multicolumn{9}{|c|}{ Análises de Regressão } \\
\hline & \multicolumn{3}{|c|}{$\mathrm{SO}_{2}-\mathrm{R}^{2} 62,1 \%$} & \multicolumn{3}{|c|}{$C O-R^{2} 56,2 \%$} & \multicolumn{3}{|c|}{$P I-R^{2} 16,2 \%$} \\
\hline 2014 & Coef. & $\begin{array}{c}\text { Erro } \\
\text { Padrão }\end{array}$ & $\operatorname{Pr}(>|t|)$ & Coef. & $\begin{array}{c}\text { Erro } \\
\text { Padrão }\end{array}$ & $\operatorname{Pr}(>|t|)$ & Coef. & $\begin{array}{c}\text { Erro } \\
\text { Padrão }\end{array}$ & $\operatorname{Pr}(>|\dagger|)$ \\
\hline CHUVA & $-0,0567$ & 0,081 & 0,486 & $-0,251$ & 0,0536 & $1,50 \mathrm{E}-05$ & $-0,097$ & 0,0467 & 0,043 \\
\hline TEMP & 1,1562 & 0,4578 & 0,014 & 0,4541 & 0,3003 & 0,1353 & $-0,147$ & 0,2816 & 0,603 \\
\hline VENT. VEL & $-0,1543$ & 0,16 & 0,338 & $-0,713$ & 0,1091 & $1,10 \mathrm{E}-08$ & 0,0642 & 0,0741 & 0,389 \\
\hline VENT. DIR & - & - & - & 0,6369 & 0,228 & 0,0069 & 0,2113 & 0,2075 & 0,312 \\
\hline T.O. & $-2,6336$ & 0,3588 & $4,00 \mathrm{E}-10$ & 1,8686 & 0,2509 & $2,80 \mathrm{E}-10$ & - & - & - \\
\hline \multirow[t]{2}{*}{ VERT } & 0,2663 & 0,1075 & 0,016 & $-0,597$ & 0,0711 & $5,70 \mathrm{E}-12$ & 0,092 & 0,041 & 0,028 \\
\hline & \multicolumn{9}{|c|}{ Análises dos resíduos } \\
\hline TesteF & 21,6 & - & $9,43 E-13$ & 13,9 & - & $4,18 \mathrm{E}-10$ & 2,55 & - & 0,036 \\
\hline Outlier Test & $-2,51$ & - & 0,014 & $-3,13$ & - & 0,002 & $-3,07$ & - & 0,003 \\
\hline $\begin{array}{l}\text { Shapiro-Wilk } \\
\text { (Normalidade) }\end{array}$ & 0,98 & - & 0,488 & 0,98 & - & 0,58 & 0,98 & - & 0,78 \\
\hline
\end{tabular}

Fonte: Elaborado pelos autores a partir de dados do INMET e SMAC.

\section{Análise conjunta dos 3 anos $(2012,2013$ e 2014)}

Nas análises de correlação dos anos de forma conjunta (Tabela 7) a precipitação pluvial seguiu o mesmo comportamento dos anos individuais, contribuindo para a redução dos poluentes na atmosfera, comportamento confirmado pelas análises de regressão (Tabela 8). A temperatura seguiu, sobretudo, o comportamento de 2012 , apresentando correlação negativa com CO $(-0,13)$ e positiva com SO2 $(0,16)$, tendo poder explicativo para os três poluentes. Já os parâmetros morfológicos contribuíram na explicação da concentração de todos os poluentes. A TO e a VERT foram associadas a um aumento de CO $(0,11$ e 0,16 , respectivamente) e a uma redução de PI (-0,26 e -0,15, respectivamente), uma relação que não emergiu nas avaliações dos anos de forma isolada. O SO2 por outro lado teve correlação positiva com a verticalização $(0,11)$, sugerindo uma possível dificuldade de dispersão do poluente em áreas mais verticalizadas, o que contrariou o resultado dos anos de forma individual. 
Tabela 4 - Análises de Correlação de Pearson dos 3 anos

\begin{tabular}{cccc}
\hline 3 anos & SO2 & CO & PI \\
\hline CHUVA & $-0,23^{* *}$ & $-0,06$ & $-0,35^{* *}$ \\
TEMP & $0,16^{*}$ & $-0,13$ & $-0,07$ \\
TO & 0,03 & $0,11^{*}$ & $-0,26^{* *}$ \\
VERT & 0,11 & 0,16 & $-0,15^{*}$
\end{tabular}

Fonte: Elaborado pelos autores a partir de dados do INMET e SMAC.

Tabela 5 - Análises descritivas e de Regressão dos 3 anos

\begin{tabular}{|c|c|c|c|c|c|c|c|c|c|}
\hline 3 anos & \multicolumn{9}{|c|}{ Análises Descritivas } \\
\hline Polventes & \multicolumn{3}{|c|}{ SO2 } & \multicolumn{3}{|c|}{$\mathrm{CO}$} & \multicolumn{3}{|c|}{ PI } \\
\hline Mediana & \multicolumn{3}{|c|}{3,11} & \multicolumn{3}{|c|}{0,3791} & \multicolumn{3}{|c|}{33,9} \\
\hline Média & \multicolumn{3}{|c|}{4,136} & \multicolumn{3}{|c|}{0,3751} & \multicolumn{3}{|c|}{35,2} \\
\hline Desvio & \multicolumn{3}{|c|}{3,102} & \multicolumn{3}{|c|}{0,1603} & \multicolumn{3}{|c|}{9,095} \\
\hline \multirow[t]{2}{*}{$\begin{array}{l}\text { Coef. de } \\
\text { variação }\end{array}$} & \multicolumn{3}{|c|}{1,333} & \multicolumn{3}{|c|}{2,465} & \multicolumn{3}{|c|}{3,87} \\
\hline & \multicolumn{9}{|c|}{ Análises de Regressão } \\
\hline 3 anos & Coef. & $\begin{array}{c}\partial_{2}-R^{2} 10, \\
\text { Erro } \\
\text { Padrão }\end{array}$ & $\begin{array}{l}2 \% \\
\operatorname{Pr}(>|t|)\end{array}$ & Coef. & $\begin{array}{c}\text { Erro } \\
\text { Eadrão }\end{array}$ & $\begin{array}{l}3 \% \\
\operatorname{Pr}(>|t|)\end{array}$ & Coef. & $\begin{array}{c}\text { P - } \mathbf{R}^{2} 21 \text {, } \\
\text { Erro } \\
\text { Padrão }\end{array}$ & $\begin{array}{l}0 \% \\
\operatorname{Pr}(>|t|)\end{array}$ \\
\hline CHUVA & $-0,2276$ & 0,0512 & $1,40 \mathrm{E}-05$ & $-0,028$ & 0,0318 & 0,374 & $-0,064$ & 0,0182 & 0,00056 \\
\hline TEMP & 0,7894 & 0,45 & 0,081 & $-0,434$ & 0,2772 & 0,119 & $-0,038$ & 0,151 & 0,79953 \\
\hline TO & - & - & - & 0,1619 & 0,071 & 0,024 & $-0,173$ & 0,0393 & $1,70 E-05$ \\
\hline \multirow[t]{2}{*}{ VERT } & 0,0649 & 0,0266 & 0,015 & $-0,103$ & 0,0532 & 0,053 & 0,097 & 0,0293 & 0,0011 \\
\hline & \multicolumn{9}{|c|}{ Análises dos resíduos } \\
\hline TesteF & 8,01 & - & 4,39E-05 & 1,95 & - & 0,104 & 13,9 & - & $4,53 \mathrm{E}-10$ \\
\hline Outlier Test & $-2,84$ & - & 0,004 & $-3,3$ & - & 0,001 & 3,06 & - & 0,002 \\
\hline $\begin{array}{l}\text { Shapiro-Wilk } \\
\text { (Normalidade) }\end{array}$ & 0,99 & - & 0,188 & 0,98 & - & 0,016 & 0,99 & - & 0,59 \\
\hline
\end{tabular}

Fonte: Elaborado pelos autores a partir de dados do INMET e SMAC.

\section{O papel da forma urbana na polvição atmosférica: Conclusões sobre o caso da cidade do Rio de Janeiro}

Constatamos que os resultados apontam para a relevância dos aspectos de percentual verticalização e taxa de ocupação na concentração dos poluentes nos casos estudados, conclusão que corrobora com achados de Endussurya (2006). Em muitos de nossos achados esses fatores apresentaram correlações mais fortes com os poluentes do que com aspectos ambientais, como a precipitação pluvial, a temperatura e a direção ou velocidade dos ventos. Entretanto, a TO não pôde ser envolvida na explicação da variação de PI em 2014 e a VERT só não teve participação explicada na variação de SO2 em 2013.

Indícios de impacto da TO na concentração dos poluentes puderam ser observados na maioria dos modelos de regressão propostos e o parâmetro apresentou correlações significativas na maioria das análises:

- Apesar dos padrões de impacto não terem sido perfeitamente consistentes, genericamente, o aumento da TO parece associado ao acúmulo de PI e a uma redução de SO2. Como as principais fontes de emissão de PI encontram-se espalhadas pela cidade, é possível indicar que o aumento da 
ocupação esteja dificultando a ventilação e, portanto, favorecendo o acúmulo dos poluentes, como também sugerido por autores aqui citados.

- Considerando que as indústrias são a principal fonte de SO2, o achado em relação a ele tende a refletir o fato delas localizarem-se em áreas menos ocupadas, onde a legislação permite e o valor do solo é baixo.

- Por sua vez o CO parece ser pouco ou nada associado com a TO.

Nossa abordagem também detectou indícios de impacto do percentual de verticalização (VERT) sobre a presença de poluentes no ar:

- A VERT teve seu aumento associado à redução de CO e ao acúmulo de PI. Assim como no caso da TO, o aumento da presença de edificações verticalizadas pode ter dificultado os movimentos de ar que auxiliariam na dispersão e diluição dos poluentes, como indicado pela literatura. Um indicativo de que esse pode ser o caso é a forte correlação negativa (-0,71 em média) que a velocidade do vento apresentou nas análises realizadas em 2014.

- Quanto à redução de CO, é possível que o aumento da presença de edificações esteja associado a tipos morfológicos que incentivem viagens a pé e a utilização do transporte público, reduzindo, portanto, a emissão do poluente. Essa possibilidade demanda mais investigações centradas na tipologia arquitetônica.

No que se refere aos parâmetros ambientais, o comportamento da precipitação corroborou as indicações da literatura e seu aumento foi associado a uma redução dos poluentes em todas as análises, certamente por ter contribuído com a deposição dos mesmos. Curiosamente, apesar do ano de 2013 ter sido o mais chuvoso dos três, não foi nele que as correlações negativas da chuva com os poluentes foram mais altas. Nesse ano a precipitação pluviométrica esteve pouco envolvida na explicação de $\mathrm{CO}$ e SO2. Talvez esses resultados sejam explicados pela distribuição assimétrica da chuva ao longo desse ano.

A temperatura apresentou correlações negativas com CO e PI e positivas com SO2. Tendo em vista a identificação de CO e PI com áreas mais ocupadas e a de SO2 com áreas menos ocupadas, imagina-se que, nas áreas mais ocupadas, o aumento da temperatura tenha favorecido os movimentos de ar verticais que auxiliaram na dispersão dos poluentes, já nas áreas menos ocupadas, o incremento da temperatura pode ter estado associado à criação de um domo de poeira que facilitou o acúmulo dos poluentes.

Por fim, apesar da limitação de dados só ter permitido a análise da ventilação em 2014, observamos uma associação negativa dos poluentes com sua velocidade, o que indica que essa variável favoreceu a dispersão dos poluentes naquele ano no Rio de Janeiro, como apontado pela bibliografia em geral. Já a direção dos ventos foi associada positivamente com SO2, revelando um possível aporte do poluente de outros locais.

De modo geral, percebemos que os resultados corroboram a hipótese deste trabalho ao revelarem não só grau de coincidência entre as variáveis morfológicas e a concentração dos poluentes, mas também trazerem indícios da existência de relações de impacto mais amplo, envolvendo efeitos indiretos de condições 
microclimáticas. Naturalmente, não podemos afirmar uma relação de absoluta causalidade, que só pode ser aferida em ambiente controlado. Este certamente não é o caso da nossa pesquisa, que trabalha com dados empíricos em ambiente complexo, não controlado, e foca num único caso, na cidade do Rio de Janeiro.

Mesmo que o poder explicativo da maior parte dos modelos não tenha sido alto e que o número de casos não permita uma extrapolação dos resultados para outras cidades no país, os achados da pesquisa devem ser úteis na medida em que apontam empiricamente para a influência de variáveis morfológicas pouco contempladas pela literatura no estudo da qualidade do ar.

0 trabalho ainda buscou contribuir com uma abordagem que possa ser replicada e ampliada em outras investigações, de modo a incluir outras variáveis de interesse ou mais precisas, sobretudo em termos arquitetônicos e de morfologia urbana, tais como a tipologia, continuidade de fachadas, a distância entre as edificações, a permeabilidade do tecido urbano ao vento, a altura precisa das edificações, etc. Essas e outras variáveis morfológicas permitiriam a identificação, ainda não alcançada por essa pesquisa, de tipos morfológicos mais ou menos favoráveis à aglutinação/dispersão dos poluentes. Em investigações subsequentes, ainda seria interessante acrescentar mais aspectos ambientais, como a umidade e outros relativos à concentração de fontes emissoras, que pudessem contribuir na explicação da concentração dos poluentes, tornando mais clara a participação dos aspectos da forma física urbana.

Ressaltamos, por fim, a urgência da continuidade de pesquisas nesse campo e da busca de evidências basilares para ampliar nosso conhecimento da relação entre cidade e ambiente. É só através delas que poderemos contribuir na elaboração de políticas públicas e legislações urbanísticas que auxiliem efetivamente na redução dos impactos ambientais negativos do funcionamento urbano, como na melhoria da qualidade do ar em nossas cidades.

\section{Referências}

Adler, F.R., \& Tanner, C. J. (2015). Ecossistemas Urbanos. São Paulo: Oficina de Textos.

Adolphe, L. (2001). A Simplified Model of Urban Morphology: Application to an Analysis of the Environmental Performance of Cities. Environment and Planning B: Planning and Design, 28(2), 183-200.

http://dx.doi.org/10.1068/b2631

Albuquerque, C.T. (2014). Análise Microclimática em diferentes condições de urbanização, na Baixada de Jacarepaguá, Rio de Janeiro - RJ (Dissertação de Mestrado). Faculdade de Ciências Sociais, Pontifícia Universidade Católica do Rio de Janeiro, Rio de Janeiro.

Barbosa, G.S., Rossi, A.M.G., \& Drach, P.R.C. (2014). Análise de Projeto Urbano a partir de parâmetros urbanos sustentáveis: alteração morfológica de Copacabana e algumas de suas consequências climáticas (1930-1950-2010). urbe. Revista Brasileira de Gestão Urbana, 6(583), 275-287. http://dx.doi.org/10.7213/urbe.06.003.ac01

Carvalho, V.S.B., Waldheim, P.V., \& Maia, L.F.P.G. (2002). Avaliação das parcelas de inaláveis no material particulado coletado pela FEEMA na Bacia Aérea III da Região Metropolitana do Rio de Janeiro. In Anais do XII Congresso Brasileiro de Meteorologia. Foz do Iguaçu: CBMet.

Castro, H.A., Gouveia, N., \& Escamilla-Cejudo, J. (2003). Questões metodológicas para a investigação dos efeitos da poluição do ar na saúde. Rev. Bras. Epidemiol., 6(2), 135-149. http://dx.doi.org/10.1590/S1415-790X2003000200007

Chan, L.Y., \& Kwok, W.S. (2001). Roadside suspended particulates at heavily trafficked urban sites of Hong Kong: seasonal variation and dependence on meteorological conditions. Atmospheric Environment, 35(18), 3177-3182. https://doi.org/10.1016/S1352-2310(00)00504-5 
Duchiade, M.P. (1992). Poluição do ar e doenças respiratórias: uma revisão. Cad. Saúde Pública, 8(3), 311-30. http://dx.doi.org/10.1590/S0102-311X1992000300010

Echenique, M.H., Hargreaves, A.J., Mitchell, G., \& Namdeo, A. (2012). Growing Cities Sustainably: Does Urban Form Really Matter? Journal of The American Planning Association, 78(2), 121-137.

https://doi.org/10.1080/01944363.2012.666731

Edussuriya, Priyantha S. (2006). Urban morphology and air quality: a study of street level air pollution in dense residential environments of Hong Kong (Tese de Doutorado). Universidade de Hong Kong, Hong Kong.

Ewing, R, \& Cervero, R. (2010). Travel and built environment: A metaanalysis. Journal of The American Planning Association, 76(3), 265-294. https://doi.org/10.1080/01944361003766766

Farias, H.S. (2013). Bacias Aéreas: uma proposta metodológica para o estudo da qualidade do ar em áreas influenciadas pelo relevo. Revista Brasileira de Climatologia, 12(9), 48-60. http://dx.doi.org/10.5380/abclima.v12i1.30081

Fundação Estadual de Engenharia do Meio Ambiente - FEEMA (2004). Inventário de fontes emissoras de poluentes atmosféricos da região metropolitana do Rio de Janeiro. Rio de Janeiro: FEEMA.

Frank, L.D., \& Engelke, P. (2005). Multiple impacts of the built environment on public health: Walkable places and the exposure to air pollution. International Regional Science Review, 28(2), 193-216.

https://doi.org/10.1177/0160017604273853

Frank, L.D., Jr., B.S., \& Bachman, W. (2000). Linking land use with household vehicle emissions in the central Puget Sound: Methodological framework and findings. Transportation Research: D, 5(3), 173-196. https://doi.org/10.1016/S1361-9209(99)00032-2

Frank, L.D., Sallis, J.F., Conway, T.L., Chapman, J.E., Saelens, B.E., \& Bachman, W. (2006). Many pathways from land use to health: associations between neighborhood walkability and active transportation, body mass index, and air quality. Journal of the American Planning Association, 72(1), 75-87. https://doi.org/10.1080/01944360608976725

Frumkin, H, Frank, L.D., Jackson, R. (2004). The public health impacts of sprawl. Washington, DC: Island Press.

Galloway, J. N. (1996). Anthropogenic mobilization of sulphur and nitrogen: Immediate and delayed consequences. Annual review of energy and the environment, 21(1), 261-292.

https://doi.org/10.1146/annurev.energy.21.1.261

Governo do Estado do Rio de Janeiro (GERJ). Instituto Estadual do Ambiente (INEA). Portal do INEA. Recuperado em 22 de dezembro de 2015, de www.inea.rj.gov.br/

Givoni, B. (1998). Climate Considerations in Building and Urban Design. USA: Wiley Pub.

Graedel, T.E., \& Crutzen, P.J. (1997). Atmosphere Climate and Change. New York: Scientific American Library.

Hoek, G., \& Brunekreef, B. (1993). Acute effects of a winter air pollution episode on pulmonary function and respiratory symptoms of children. Archives of Environmental Health: An International Journal, 48(5), 328-335. https://doi.org/10.1289/ehp11813

Instituto Estadual do Meio Ambiente (INEA) (2015). Governo do Rio de Janeiro. Relatório da Qualidade do Ar do Estado do Rio de Janeiro: Ano base 2012. Rio de Janeiro: INEA.

Instituto Nacional de Meteorologia (INMET) (2015). Instituto Nacional de Meteorologia (INMET). Recuperado em 01 de dezembro de 2015, de http://www.inmet.gov.br/

Lam, G.C.K., Leung, D.Y.C, Niewiadomski, M., Pang, S.W., Lee, A.W.F., \& Louie, P.K.K. (1999). Street-level concentrations of nitrogen dioxide and suspended particulate matter in Hong Kong. Atmospheric Environment, 33(1), 1-11.

https://doi.org/10.1016/S1352-2310(98)00114-9

Landsberg, H.E. (1997). The urban climate. New York: Academic Press.

Larrañaga, A.M., Ribeiro, J. L. D., \& Cybis, H. B. B. (2009). Fatores que afetam as decisões individuais de realizar viagens a pé: estudo qualitativo. Revista Transportes, 17(2), 16-26. https://doi.org/10.14295/transportes.v17i2.355

Maia, J.L.M. (2016). Impactos de Padrões Morfológicos na concentração de poluentes atmosféricos: o caso da cidade do Rio de Janeiro. (Dissertação de Mestrado). Faculdade de Arquitetura e Urbanismo, Universidade Federal Fluminense, Niterói. 
Maia, J.L.M., \& Netto, V.M. (2016). Forma Urbana: Uma discussão sobre Compacidade e Desempenho. In Anais IV Encontro de Sustentabilidade Em Projeto (p.152 - 163). Florianópolis: UFSC.

Martins, M. F., \& Cândido, G. A. (2015) Modelo de avaliação do nível de sustentabilidade urbana: proposta para as cidades brasileiras. Urbe. Revista Brasileira de Gestão Urbana, 7(3), 397-410. http://dx.doi.org/10.1590/21753369.007.003.ao09

McPhearson, T., Pickett, S. T. A., Grimm, N. B., Niemelä, J., Alberti, M., Elmqvist, T., Weber, C., Haase, D., Breuste, J., \& Qureshi, J. (2016). Advancing Urban Ecology toward a Science of Cities. BioScience, 66(3), 198-212. https://doi.org/10.1093/biosci/biw002

Ministério do Meio Ambiente (MMA) (1990, 28 de junho). Resolução CONAMA n. 3, de 28 de junho de 1990. Dispõe sobre Padrões de Qualidade do Ar, Previstos no Pronar. Brasília: Diário Oficial da União, seção 1, 15.937-15.939.

Newman, P.W.G, \& Kenworthy, J.R. (1989). Gasoline Consumption and Cities: A Comparison of U.S. Cities with a Global Survey. Journal of The American Planning Association, 55 (1), 24-37. https://doi.org/10.1080/01944368908975398

Netto, V. M., Vargas, J.C. \& Saboya, R.T. (2012). (Buscando) Os efeitos sociais da morfologia arquitetônica. urbe. Revista Brasileira de Gestão Urbana, 4(2), 261-282. http://dx.doi.org/10.7213/urbe.7400

Netto, V. M., Vargas, J.C. \& Saboya, R.T. (2019). The social effects of architecture: built form and social sustainability. In M. R. Shirazi and R. Keivani (Org.) Urban Social Sustainability: Theory, Policy and Practice. London: Routledge, 125-148.

Oke, T.R. (1987). Boundary layer climates (2a ed.). Methuen: London \& New York.

Pan, H., Bartolome, C., Princevac, M., \& Edwards, R. (2010). Influence of Urban Morphology on street level concentrations: water channel and field study in three southern Californian cities. Recuperado em 12 de janeiro de 2016, de www.researchgate.net/profile/Hansheng_Pan/publication/242567291_INFLUENCE_OF_URBAN_MORPHOLOGY_ON_S TREET_LEVEL_CONCENTRATIONS_WATER_CHANNEL_AND_FIELD_STUDY_IN_THREE_SOUTHERN_CALIFORNIAN_CIT IES/links/02e7e53c353d55f5c5000000.pdf.

Pimentel, L.C.G., Marton, E., Silva, M.S., \& Jourdan, P. (2014). Caracterização do regime de vento em superfície na Região Metropolitana do Rio de Janeiro. Engenharia Saniária Ambiental, 19(2), 121-132. http://dx.doi.org/10.1590/S1413-41522014000200003

Robaa, S.M. (2003). Urban-suburban/rural differences over Greater Cairo, Egypt. Atmósfera, 16(3), 157-171.

Salat, S. (2009). Energy loads, CO2 emissions and building stocks: morphologies, typologies, energy systems and behaviour. Building Research \& Information, 37(5-6),598-609. https://doi.org/10.1080/09613210903162126

Shumway, R.H., Azari, A.S., \& Pawitan, Y. (1988). Modelling mortality fluctuations in Los Angeles as functions of pollution and weather effets. Environmental Research, 45, 224-241.

Tângari, V.R., Rego, A.Q, Dias, M.A., Rheingantz, P.A., Azevedo, G.A.N., Montezuma, R.C.M. Souza, M.J.N., Schlee, M.B., Caderman, R., Wopereis, B., Capillé, C.C., Parahuba, N., \& Amorim, M. (2011). Morfologia Urbana, Suporte Geo-Bio Físico e o Sistema de Espaços Livres no Rio De Janeiro. In A.C.A. Campos, E.F. Queiroga, F. C. Galender, H.N. Degreas, R. Akamine, S.S. Macedo, \& V. Custódio (Org.). Quadro dos sistemas de Espaços livres nas cidades brasileiras (1 ed., p. 195239). São Paulo: FAU USP.

Editor responsável: Paulo Nascimento Neto

Recebido: 25 jul. 2018

Aprovado: 18 ago. 2019 